\title{
METABOLISMO DO NITROGÊNIO ASSOCIADO À DEFICIÊNCIA HÍDRICA E SUA RECUPERAÇÃO EM GENÓTIPOS DE MILHO ${ }^{1}$
}

\author{
NITROGEN METABOLISM ASSOCIATED TO WATER DEFICIT AND ITS RECOVERY \\ IN MAIZE GENOTYPES
}

\begin{abstract}
Vilma Marques Ferreira ${ }^{2}$ Paulo César Magalhães ${ }^{3}$ Frederico Ozanan Machado Durães ${ }^{4}$ Luiz Edson Mota de Oliveira ${ }^{5}$ Antonio Álvaro Corsetti Purcino ${ }^{4}$
\end{abstract}

\section{RESUMO}

$O$ estresse hídrico afeta profundamente o metabolismo celular vegetal. Neste trabalho, objetivou-se quantificar os efeitos da deficiência hídrica e sua recuperação sobre a atividade das enzimas do metabolismo do nitrogênio: redutase do nitrato $(R N)$, glutamina sintetase $(G S)$ e glutamato sintase (GOGAT) e sobre o acúmulo de prolina em plantas dos genótipos de milho BR 2121 e BR 205. O experimento foi conduzido em casa de vegetação, sob o delineamento inteiramente casualizado, com quatro repetições, utilizando-se vasos que continham $14,3 \mathrm{~kg}$ de solo. Os tratamentos consistiram da combinação dos dois genótipos e quatro intervalos entre irrigações (1, 3, 5 e 7 dias). No dia da avaliação (49 dias após emergência), os tratamentos com intervalos entre 3 e 7 dias, haviam sido irrigados no dia anterior, caracterizando-se portanto como recuperação da deficiência hídrica leve e severa, respectivamente. As extrações e análises foram realizadas utilizando-se a terceira folha basípeta completamente expandida. As atividades das enzimas estudadas não diferiram entre os tratamentos de estresse hídrico, controle e recuperação do estresse moderado, entretanto as plantas sob recuperação do estresse severo apresentaram atividade enzimática superior à das plantas controle. $O$ acúmulo de prolina livre nas folhas aumentou com o estresse hídrico e respondeu à recuperação do estresse apresentando redução. De modo geral, a atividade enzimática e o acúmulo de prolina apresentaram respostas inversas dentro dos tratamentos.

Palavras-chave: nitrogênio, estresse hídrico, prolina, Redutase do nitrato, GS, GOGAT.

\section{SUMMARY}

Water stress affects deeply plant cell metabolism. The objective of this work was to quantify the effects of water deficits and its recovery on the performances of nitrogen metabolism enzymes: nitrate reductase (NR), glutamine sintethase (GS) and glutamate sintase (GOGAT) and an accumulation of proline in maize genotypes $B R 2121$ and BR 205. The trial was carried out in greenhouse, by using pots with $14.3 \mathrm{~kg}$ of soil. The treatments performed were a combination of two genotypes and four intervals among irrigation $(1,3,5$ and 7 days). On the day in which the treatments were evaluated (49 days after emergency), there was irrigation on the treatments with intervals of 3 and 7 days, therefore those treatments were considered as light and severe recovery of water deficit, respectively. The extractions and analysis were performed by taking the third leaf completely expanded from top to down. The activities of enzymes did not differ among water deficit treatments, control and recovery of severe stress showed higher enzymatic activity than control. The accumulation of free proline in the leaves increased with deficit and responded to recovery of water deficit by reducing its content. In general, the enzimatic activity and the proline accumulation showed inverse answers within treatments.

Key words: nitrogen, water deficit, proline, nitrate reductase, GS, GOGAT.

\section{INTRODUÇÃO}

A assimilação do nitrogênio é um processo vital que controla o crescimento e o desenvolvimento das plantas e tem efeitos marcantes

\footnotetext{
${ }^{1}$ Parte da dissertação apresentada pela primeira autora à Universidade Federal de Lavras (UFLA) para obtenção do título de Mestre em Agronomia/Fisiologia Vegetal (Bolsa concedida pela CAPES).

${ }^{2}$ Engenheiro Agrônomo, Mestre, Doutorando em Agronomia/Produção Vegetal, Universidade Estadual de São Paulo, Jaboticabal, SP.

${ }^{3}$ Engenheiro Agrônomo, PhD., Pesquisador da Embrapa Milho e Sorgo, CP 151, 35701-970, Sete Lagoas, MG. E-mail: pcesar@cnpms.embrapa.br. Autor para correspondência.

${ }^{4}$ Engenheiro Agrônomo, Doutor, Pesquisadores da Embrapa Milho e Sorgo.

${ }^{5}$ Engenheiro Agrônomo, Doutor, Professor titular, Departamento de Biologia da UFLA, Lavras, MG.
} Recebido para publicação em 05.03.01. Aprovado em 09.05.01 
sobre a fitomassa e a produtividade final das culturas. A rota de assimilação do nitrato em plantas superiores envolve dois estágios seqüenciais. A conversão do nitrato à amônia, mediada pela nitrato redutase $(\mathrm{RN})$, a qual reduz nitrato a nitrito, e pela nitrito redutase, que converte nitrito à amônia. A amônia é então assimilada nos aminoácidos glutamina e glutamato, os quais servem para translocar nitrogênio orgânico de fontes para drenos. As principais enzimas envolvidas são a glutamina sintetase (GS) e a glutamato sintase (GOGAT) (LAM et al., 1996).

A GS ocorre em folhas de milho como duas isoformas: uma citoplásmica (GS1) e outra cloroplastídica (GS2) (YAMAYA \& OAKS, 1988). Aparentemente, o papel da GS2 é assimilar a amônia gerada a partir da redução do nitrato ou liberada durante o processo de fotorrespiração da glicina (MIFLIN \& LEA, 1980), enquanto altos níveis de atividade de GS1 são observados em resposta ao acúmulo de amônia devido ao processo de degradação de proteínas em plantas senescentes (KAWAKAMI \& WATANABE, 1988; SAKAKIBARA et $\boldsymbol{a l}$., 1992) ou sob deficiência de $\mathrm{N}$ (PURCINO et al., 1992). Duas formas de GOGAT são conhecidas em função dos seus doadores de elétrons: uma dependente de $\mathrm{NAD}(\mathrm{P}) \mathrm{H}$ $(\mathrm{NAD}(\mathrm{P}) \mathrm{H}-\mathrm{GOGAT})$ e outra dependente de ferredoxina (Fd-GOGAT). Em tecidos fotossintéticos, esta última contribui com aproximadamente $96 \%$ da atividade total da GOGAT, sendo a atividade restante derivada da NADH-GOGAT (SUZUKI \& ROTHSTEIN, 1997).

Como parte do metabolismo global das plantas, o metabolismo do nitrogênio é afetado pelo déficit hídrico. Diversos trabalhos têm mostrado como e quanto a nitrato redutase é afetada em milho. No entanto, com relação à GS e GOGAT há poucos relatos na literatura e, além disso, os resultados encontrados são contraditórios.

Alguns metabólitos nitrogenados, como o aminoácido prolina, tendem a acumular nos tecidos vegetais sob estresse hídrico. Como a assimilação do nitrogênio é reduzida sob tais condições, pode-se supor que tais compostos se originam da rotatividade de proteínas. É neste contexto que as enzimas envolvidas na incorporação de amônia a compostos orgânicos, os quais podem agir como precursores para diferentes metabólitos, podem ter importante papel na sobrevivência de plantas durante estresse.

O objetivo deste trabalho foi avaliar os efeitos do déficit hídrico no solo sobre a atividade das enzimas RN, GS e Fd-GOGAT e sobre a concentração de prolina livre em plantas dos genótipos de milho BR 2121 e BR 205.

\section{MATERIAL E MÉTODOS}

O experimento foi conduzido em casa de vegetação, na Embrapa Milho e Sorgo, Sete Lagoas - MG. A casa de vegetação apresentava cobertura plástica e sistema automático de umidificação e ventilação.

O solo utilizado foi retirado da camada superficial (aproximadamente 20cm) de um Latossolo Vermelho-Escuro álico, fase cerrado. A adubação de plantio (N, P, K e micronutrientes) foi realizada de acordo com recomendação técnica baseada nos resultados das análises químicas do solo. Aplicou-se ainda carbonato de cálcio puro para correção da acidez do solo. Quando as plantas atingiram o estádio V6 (segundo a classificação de RITCHIE $\boldsymbol{e t}$ al., 1989) fez-se a primeira adubação nitrogenada de cobertura, utilizando-se uréia como fonte de N. A segunda adubação de cobertura foi realizada no estádio $\mathrm{V} 10$.

A semeadura foi feita em vasos que continnham $14,3 \mathrm{~kg}$ de solo, cuja umidade estava em torno de $22,65 \%$, sobre uma camada de $1,5 \mathrm{~kg}$ de brita, utilizada para facilitar a drenagem da água. A emergência das plântulas ocorreu 5 dias após a semeadura (DAS). Aos 12 DAS foi feito o desbaste, deixando-se duas plantas por vaso.

$\mathrm{O}$ delineamento experimental utilizado foi o inteiramente casualizado, sob um esquema fatorial $2 \times 4$, em que os fatores estudados foram genótipos (BR 2121 e BR 205) e intervalos, em dias, para reposição da água evapotranspirada $\left(\mathrm{T}_{1}\right.$-Reposição diária, considerada como controle; $\mathrm{T}_{3}$-reposição a cada três dias; $\mathrm{T}_{5}$-reposição a cada cinco dias; $\mathrm{T}_{7^{-}}$ reposição a cada sete dias), com quatro repetições. Cada unidade experimental consistiu de um vaso contendo duas plantas.

O genótipo BR 2121 é um híbrido com qualidade protéica dos grãos melhorada, que à época da realização do experimento se encontrava em fase de lançamento, havendo necessidade de estudos fisiológicos do genótipo. Já o BR 205, também híbrido, é considerado de tolerância moderada à seca.

Os tratamentos hídricos foram iniciados quando as plantas atingiram o estádio V3, com a umidade inicial do solo na capacidade de campo, em todos os tratamentos. A quantidade de água aplicada em cada tratamento foi calculada considerando a massa atual e a massa inicial dos vasos, através de pesagens, utilizando-se uma balança digital eletrônica com capacidade máxima de $32 \mathrm{~kg}$ e sensibilidade de $1 \mathrm{~g}$.

O material vegetal utilizado para as análises (terceira folha totalmente expandida, de 
cima para baixo, de uma planta por repetição) foi coletado aos 49 dias de idade das plantas. Foi realizada a determinação das atividades das enzimas redutase do nitrato, glutamina sintetase (GS) e glutamato sintase dependente de ferredoxina ( $\mathrm{Fd}$ GOGAT) e a concentração de prolina livre. A atividade da RN foi quantificada no mesmo dia da coleta. Para as demais avaliações, o material foi congelado a $-80^{\circ} \mathrm{C}$ até à análise. A atividade da RN foi determinada pelo método in vitro, segundo LILLO (1983), a da GS segundo RHODES $\boldsymbol{e}$ t al. (1975), e ERICSON (1985) e a da Fd-GOGAT segundo LEA et al. (1990). A concentração de prolina livre foi determinada segundo metodologia descrita por BATES et al. (1973). As atividades das enzimas bem como a concentração de prolina foram expressas com base na massa seca foliar.

Como a época da coleta coincidiu com os tratamentos $\mathrm{T} 3$ e $\mathrm{T} 7$, que haviam sido irrigados no dia anterior, esses serão considerados como recuperação de estresse moderado e severo, respectivamente. $\mathrm{O}$ tratamento $\mathrm{T} 5$ é o que efetivamente estava sob deficiência hídrica.

Os resultados obtidos foram submetidos à análise de variância e, quando cabível, teste de médias (Tukey), em nível de 5\% de probabilidade de erro, com o auxílio do programa estatístico ESTAT, desenvolvido no Laboratório de Processamento de Dados da UNESP, Jaboticabal - SP.

\section{RESULTADOS E DISCUSSÃO}

A redutase do nitrato apresentou redução de sua atividade sob condições de estresse hídrico, entretanto a diferença apresentada em relação ao controle não foi estatisticamente significativa (Figura 1A) em ambos os genótipos. No tratamento sob recuperação de estresse severo, a atividade da enzima foi superior à dos demais tratamentos. Os genótipos apresentaram resposta similar ao déficit hídrico, entretanto o BR 205 apresentou atividade significativamente superior desta enzima quando comparado ao BR 2121. Isso pode estar associado ao maior potencial produtivo verificado para o BR 205, tanto em fitomassa como em produção de grãos (FERREIRA et al., 2000).

Houve interação entre genótipos e intervalos da irrigação para a atividade da GS (Figura 1B). No genótipo BR 2121, as plantas que estavam sob recuperação do estresse, tanto moderado quanto severo, apresentaram atividade enzimática superior ao controle e ao tratamento sob estresse, enquanto no genótipo BR 205 apenas as plantas sob recuperação de estresse severo mostraram atividade superior da enzima. Os genótipos diferiram entre si apenas no intervalo de 3 dias entre irrigações, quando o BR 2121 apresentou atividade superior para a enzima.

A atividade da Fd-GOGAT mostrou comportamento similar nos dois genótipos (Figura 1C). O tratamento sob recuperação de estresse severo apresentou atividade superior desta enzima, entretanto esse tipo de estresse não diferiu da recuperação de estresse moderado. A atividade da enzima não diferiu do controle e do tratamento sob estresse. A análise de variância (não apresentada) mostrou que não houve efeito estatístico do genótipo sobre esta variável.

Houve diferença entre os genótipos em relação ao acúmulo de prolina livre na folha (Figura 1D). No genótipo BR 205, a concentração deste aminoácido foi mais baixa e não diferiu entre os tratamentos. Já no BR 2121, no qual o teor foi mais elevado, houve maior acúmulo deste aminoácido no tratamento sob estresse.

Quando se comparam as respostas das atividades enzimáticas e do acúmulo de prolina livre na folha, observa-se tendência oposta, ou seja, nos tratamentos em que houve maior atividade das enzimas, o acúmulo de prolina livre foi menor e vice-versa.

A atividade superior da redutase do nitrato em condições de recuperação de estresse hídrico severo pode ter sido favorecida por um fluxo mais intenso de nitrato, em decorrência de um provável aumento no fluxo transpiratório, ocorrido após a cessação do estresse, uma vez que a atividade da enzima depende do fluxo de nitrato da raiz para as folhas e este, por sua vez, do fluxo transpiratório (SHANER \& BOYER, 1976). Embora neste trabalho não tenha sido determinada a transpiração após a reirrigação, esta suposição se baseia nas afirmações feitas por LAHIRI (1980). Segundo esse autor, após um ciclo de seca, aumenta a taxa de transpiração, sendo o aumento diretamente proporcional à intensidade do estresse. SHANER \& BOYER (1976) observaram que a atividade da RN, durante a recuperação do estresse, aproxima-se daquela do controle em plântulas de milho de 8 dias de idade, diferente do que ocorreu neste trabalho. Entretanto a idade das plantas e o próprio histórico do estresse podem ter contribuído para esta diferença.

No tratamento sob deficiência hídrica (intervalo de 5 dias entre irrigação), é provável que a ocorrência de períodos repetitivos de seca, ao longo do experimento, tenha favorecido uma adaptação que permitiu certa estabilização na atividade da enzima, cuja atividade não diferiu daquela das plantas controle. 


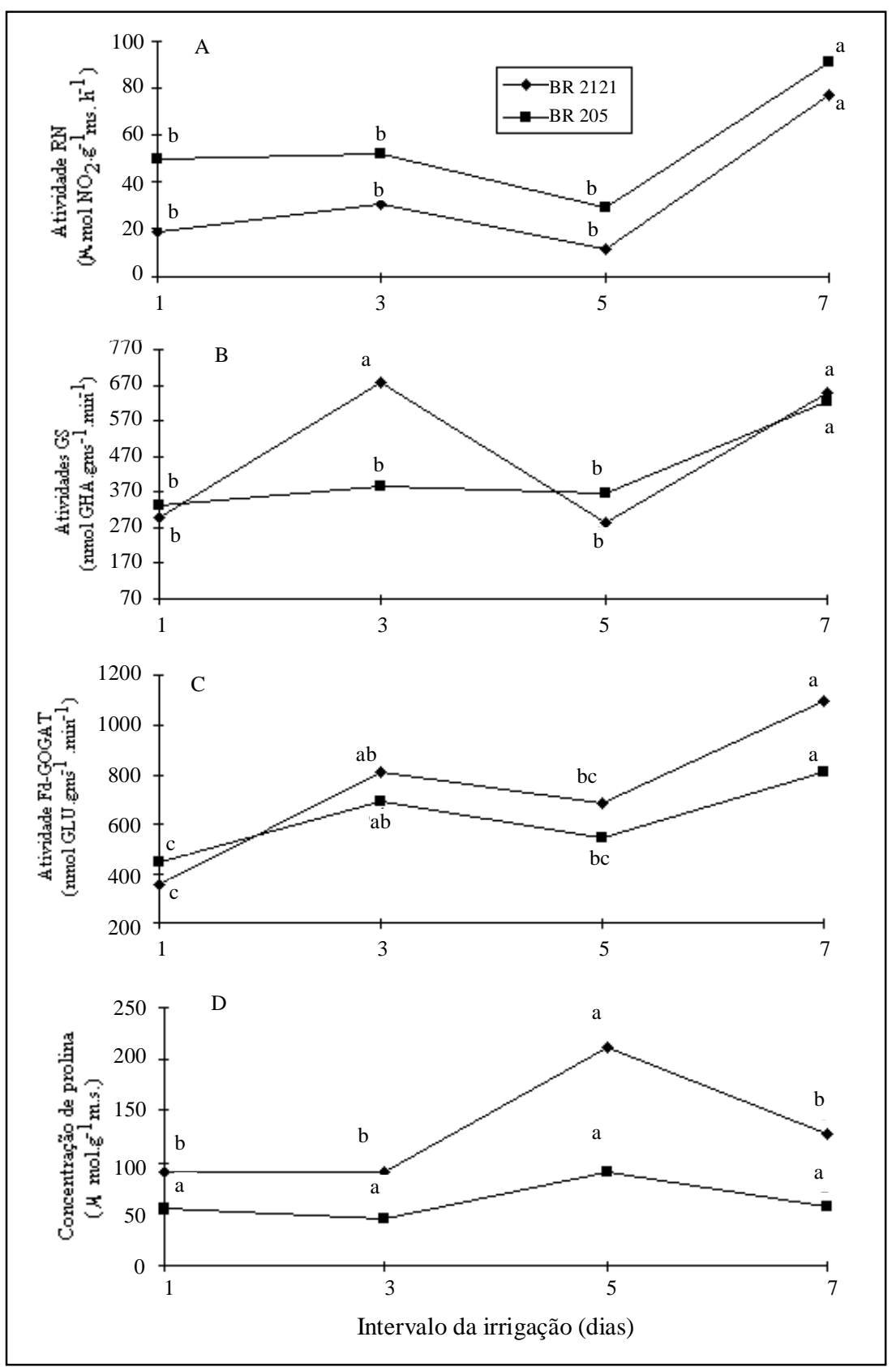

Figura 1 - Atividades das enzimas redutase do nitrato (A), glutamina sintetase (B) e glutamato sintase (C) e concentração de prolina (D) em folhas dos genótipos de milho BR 2121 e BR 205 submetidos a diferentes intervalos entre irrigações (1, 3, 5 e 7 dias). As letras comparam intervalos da irrigação dentro de genótipos, pelo teste Tukey, em nível de $5 \%$ de probabilidade de erro. A época da amostragem os tratamentos $\mathrm{T}_{3}$ e $\mathrm{T}_{7}$ estavam sob recuperação do estresse (Sete Lagoas, MG, 1996).

As atividades das enzimas GS e FdGOGAT apresentaram resposta ao estresse e à recuperação desse, similar àquela da RN. Com relação à atividade da GS, MIRANDA-HAM \& LOYOLA-VARGAS (1994) observaram aumento considerável na atividade desta enzima, em folhas de plantas de milho com 15 dias de idade, sujeitas a estresse hídrico imposto pela adição de polietileno glicol à solução nutritiva, após 6 horas do início do tratamento. Entretanto após 12 horas, a atividade da enzima retornou aos níveis do controle. Embora a natureza do trabalho e a idade das plantas não permita comparação direta, os resultados obtidos por tais autores apontam para certa adaptação da atividade da enzima após determinado período de deficiência hídrica. Tal fato pode ter ocorrido neste trabalho, no qual foi observado que a atividade da enzima não diferiu entre as plantas controle e as do tratamento sob estresse.

$\mathrm{O}$ acúmulo de prolina em plantas sob estresse pode ser conseqüência do aumento na sua síntese ou do decréscimo na sua degradação (RHODES et $\boldsymbol{a l}$., 1986). A rota metabólica responsável pela síntese de prolina mais expressiva em plantas tem início no aminoácido glutamato, o qual pode ser produzido por hidrólise de proteínas, por reações de transaminação ou pelas reações catalisadas pelo ciclo GS/GOGAT (VALPUESTA $\boldsymbol{e}$ al. 1992). No caso deste trabalho, não pode ser admitido que a prolina acumulada tenha sua origem no glutamato proveniente do $\mathrm{N}$ assimilado recentemente, ou seja, pelo ciclo GS/GOGAT, uma vez que as respostas de atividade destas enzimas ao estresse hídrico foram inversas ao acúmulo de prolina. Conseqüentemente, a disponibilidade de glutamato necessário para síntese de prolina só pode ser explicada pela hidrólise de proteínas ou por transaminação a partir de outros aminoácidos. A hidrólise de proteínas, além de contribuir com o aminoácido precursor (glutamato), pode também contribuir com a própria prolina, favorecendo o seu aumento como aminoácido livre nos tratamentos sob estresse hídrico. 


\section{CONCLUSÕES}

Em relação ao BR 2121, o genótipo BR 205 apresentou maior atividade da redutase do nitrato e menor atividade da GS apenas quando sob recuperação de estresse moderado. Não houve diferença entre os genótipos para a atividade da FdGOGAT. A concentração de prolina livre na folha foi maior em BR 2121.

As atividades das enzimas redutase do nitrato, GS e Fd-GOGAT não sofreram alteração por efeito do deficit hídrico. Entretanto as plantas sob recuperação do estresse severo apresentaram as mais altas atividades enzimáticas. A concentração de prolina livre aumentou em função da deficiência hídrica, retornando aos níveis normais com a recuperação do estresse.

\section{REFERÊNCIAS BIBLIOGRÁFICAS}

BATES, L.S., WALDREN, R.P., TEARE, I. Rapid determination of free proline for water-stress studies. Plant and soil, Netherlands, v.39, n.2, p.205-207, 1973.

ERICSON, M. Purification and properties of glutamine synthetase from spinach leaves. Plant Physiology, Maryland, v.79, p.923-927, 1985

FERREIRA, V.M., MAGALHÃES, P.C., DURÃES, F.O.M. Produtividade de genótipos de milho (Zea mays L.) sob manejo diferenciado de irrigação e adubação. Ciência e Agrotecnologia, Lavras, v.24, p.663-670, 2000.

KAWAKAMI, N., WATANABE, A. Senescence-specific increase in cytosolic glutamine synthetase in the remobilization of leaf nitrogen during natural senescence in rice leaves. Plant Physiology, Maryland, v.98, p.1323-1329, 1988.

LAHIRI, A.N. Interaction of water stress and mineral nutrition on growth and yield. In: TURNER, N.C., KRAMER, P..J. (eds.). Adaptation of plant to water and high temperature stress. New York : John Wiley \& Sons, 1980. p.87-104.

LAM, H.M., COSCHIGANO, K.T., OLIVEIRA, I.C., et al. The molecular-genetics of nitrogen assimilation into amino acids in higher plants. Annual Review of Plant Physiology and Plant Molecular Biology, Palo Alto, v.47, p.569-593, 1996.

LEA, P.J., BLACKWELL, R.D., CHEN, F., et al. Enzymes of ammonia assimilation. In: LEA, P.J. (ed.). Methods in plant biochemistry. London : Academic, 1990. V.3, p.257276.
LILLO, C. Studies of diurnal variations of nitrate reductase activity in barley using various assay methods. Physiologia Plantarum, Copenhagen, v.52, p.357-362, 1983.

MIFLIN, B.J., LEA, P.J. Ammonia assimilation. In: MIFLIN, B.J. (ed.) The biochemistry of plants: amino acids and derivatives. New York: Academic, 1980. p.169-202.

MIRANDA-HAM, M. de L., LOYOLA-VARGAS, V.M Glutamate dehydrogenase and glutamine synthetase activities in maize under water and salt stress. $\Phi$ yton, Buenos Aires, v.56, p.7-15, 1994.

PURCINO, A.A.C., SASAKAWA, H., SUGYAMA, T Enzimas do metabolismo de carbono e $\mathbf{N}$ em milho. Sete Lagoas: EMBRAPA, 1992. p.54-56. (Relatório técnico anual do centro nacional de pesquisa de milho e sorgo 1988-1991).

RHODES, D., HANDA, S., BRESSAN, R.A. Metabolic changes associated with adaptation of plant cells to water stress. Plant Physiology, Maryland, v.82, p.890-903, 1986.

RHODES, D., RENDON, G.A., STEWART, G.R. The control of glutamine synthetase level in Lemna minor L. Planta, Berlin, v.125, p.201-211, 1975.

RITCHIE, S.W., HANWAY, J.J., BENSON, G.O. How a corn plant develops. Ames : Iowa State University of Science and Technology, 1989. 21p. (Special Report, 48).

SAKAKIBARA, H., KAWABATA, S., TAKAHASHI, H., $\boldsymbol{e} \boldsymbol{t} \boldsymbol{a}$. Molecular cloning of the family of glutamine synthetase genes from maize: expression of genes for glutamine synthetase and ferredoxin-dependent glutamate synthase in photosynthetic and nonphotosynthetic tissues. Plant Cell Physiology, Kyoto, v.33, p.49-58, 1992.

SHANER, D.L., BOYER, J.S. Nitrate reductase activity in maize (Zea mays L.) leaves. I. Regulation by nitrate flux. Plant Physiology, Maryland, v.58, p.499-504, 1976.

SUZUKI, A., ROTHSTEIN, S. Structure and regulation of feredoxin-dependent glutamate synthase from Arabidopsis thaliana cloning of cDNA expression in different tissues of wild type and gltS mutant strains, and light induction. European Journal of Biochemistry, v.243, p.708-718, 1997.

VALPUESTA, V., BERTELI, F., PÉREZ-PRAT, E., $\boldsymbol{e} \boldsymbol{t} \boldsymbol{a l}$. Cambios metabólicos y de expresión génica en plantas superiores en respuesta al estrés salino. Agriscientia, v.9, p.55-63, 1992.

YAMAYA, T., OAKS, A. Distribution of two glutamine synthetase in bundle sheath and mesophyl cells of corn leaves. Physiologia Plantarum, Copenhagen, v.72, p.23-38, 1988.

Ciência Rural, v. 32, n. 1, 2002. 